\title{
1 Isothermal crystallization behaviour of lard at different 2 temperatures studied by DSC and real-time XRD
}

3

4 Liselot Steen $^{1,2}$, Annelien Rigolle ${ }^{2}$, Seline Glorieux ${ }^{1,2}$, Hubert Paelinck ${ }^{1}$, Ilse Fraeye ${ }^{1}$,

5 Bart Goderis ${ }^{3}$, Imogen Foubert ${ }^{2, *}$

6

$7 \quad{ }^{1}$ KU Leuven, Technology Campus Ghent, Leuven Food Science and Nutrition Research

8 Centre (LFoRCe), Research Group for Technology and Quality of Animal Products,

9 Gebroeders De Smetstraat 1, B-9000 Gent, Belgium

$10{ }^{2}$ KU Leuven, Kulak, Leuven Food Science and Nutrition Research Centre (LFoRCe), Foods

$11 \&$ Lipids, Etienne Sabbelaan 53, B-8500 Kortrijk, Belgium

$12{ }^{3}$ KU Leuven, Polymer Chemistry and Materials, Celestijnenlaan 200f - box 2404, B-3001

13 Leuven, Belgium

14

15

$16 *$ Correspondent footnote

17 Mailing address:

18 KU Leuven, Kulak, Leuven Food Science and Nutrition Research Centre (LFoRCe), Foods \&

19 Lipids, Etienne Sabbelaan 53, B-8500 Kortrijk, Belgium

20

21 Phone: +3256246173

22 E-mail address: Imogen.Foubert@kuleuven-kulak.be 
25 Differential scanning calorimetry and real-time X-ray diffraction using synchrotron radiation 26 were used to study the isothermal crystallization formation mechanism of lard at 18, 20, 22 and $24^{\circ} \mathrm{C}$. At $18^{\circ} \mathrm{C}$, lard crystallized in three steps. A potential mechanism for these three steps was proposed. In the first step, part of the melt (the trisaturated triacylglycerols (TAGs)) crystallized in $\alpha$ crystals adopting a double length structure $(2 \mathrm{~L})$, while the second step consisted of a polymorphic transition of these $2 \mathrm{~L} \alpha$ crystals to $\beta$ ' crystals with a triple length structure (3L). Extra 3L $\beta$ ' crystals consisting of monounsaturated TAGs were also formed

32 directly from the melt. In the third and last step, $\beta$ crystals were formed due to a second 33 polymorphic transition of trisaturated $3 \mathrm{~L} \beta$ ' crystals to $\beta$ crystals adopting a $2 \mathrm{~L}$ structure. 34 Above a cut-off temperature of $20^{\circ} \mathrm{C}$ lard crystallized in two steps: no formation of $\alpha$ crystals could be observed and $3 \mathrm{~L} \beta$ ' crystals (trisaturated and monounsaturated TAGs) were formed directly from the melt. This proposed mechanism implies that lard crystallization is characterized by an overlap of fractionated crystallization and polymorphic transitions.

Keywords: lard, polymorphism, fractionated crystallization, crystallization mechanism 


\section{Introduction}

Lard is the fat obtained from the adipose tissue of the pig by a rendering process. It is used in many industrial bakery applications like biscuits, cakes and cookies (deMan et al., 1991). Furthermore, lard or adipose tissue is also an important ingredient in spreadable liver paste, a warm processed fine emulsion-like meat product (Steen et al., 2014b). Lard's crystallization properties have a large impact on the quality of these lard containing products. It has, e.g. in spreadable liver paste, been shown, that fat crystallization not only affects the sensorial properties and stability but also determines to a large extent the rheological and structural properties (Steen et al., 2014a,b). Knowledge of the (isothermal) crystallization properties of lard is thus hugely important to better control product quality and optimize production processes.

The major fatty acids in lard are 20-29\% C16:0 (palmitic acid, P), 11-19\% C18:0 (stearic acid, St), 24-51\% C18:1 (oleic acid, O) and 3-19\% C18:2 (linoleic acid, L) (Marikkar \& Yanty, 2014). Di- (UUS, with U: unsaturated and S: saturated) and monounsaturated (USS) triacylglycerols (TAGs) are the most dominant TAG groups. The former account for $47-54 \%$ with OPO and OPL being the most important TAGs in this group. The latter group makes up 24-27\% of the TAGs with OPP and OPSt being the main representatives. Lard also contains 18-24\% triunsaturated TAGs (UUU) and 2-10\% trisaturated TAGs (SSS, mainly PPSt and PStSt) (Kallio et al., 2001; Keller et al., 1996; Marikkar \& Yanty, 2014). Lard is unique among other fats, because the saturated fatty acids are preferentially located in the $s n-2$ position whereas the unsaturated fatty acids are mostly located on the external positions (AlRashood et al., 1996; Kalnin et al. 2005). It should also be noted that the chemical composition of lard can vary widely and is influenced by rearing factors including feeding, breed, sex, age and physiological stage (Kincs, 1985; Gandemer, 2002).

Several authors have investigated the non-isothermal crystallization behaviour of lard with differential scanning calorimetry (DSC) and observed that the TAG composition, consisting of high and low melting TAGs, leads to a broad melting range $\left(-30\right.$ and $\left.50^{\circ} \mathrm{C}\right)$ with up to six melting peaks and two or three crystallization peaks between 20 and $-50^{\circ} \mathrm{C}$, depending on the heating and cooling rate (Kalnin et al., 2005; Keller et al., 1996; Svenstrup et al., 2005; Santacatalina et al., 2011). The crystallization behaviour of lard is complicated because of the polymorphism of the solid phase. With X-ray diffraction (XRD), Kalnin et al. (2005) identified four polymorphic forms in lard: $\alpha, \beta^{\prime}{ }_{1}, \beta^{\prime}{ }_{2}$ and $\beta$ in order of increasing 
stability. Furthermore, the polymorphic form of lard is to a large extent determined by the rate of cooling and the final temperature. Campos et al. (2002) found $\beta$ ' and $\beta$ polymorphs in samples that are cooled slowly $\left(0.1^{\circ} \mathrm{C} / \mathrm{min}\right)$ while only $\beta^{\prime}$ crystals were observed when lard is crystallized rapidly $\left(5^{\circ} \mathrm{C} / \mathrm{min}\right)$. They, however, did not show the XRD results. Kalnin et al. (2005) reported that a high cooling rate $\left(5^{\circ} \mathrm{C} / \mathrm{min}\right)$ results in unstable $\alpha$ polymorphs which subsequently transform into $\beta^{\prime}$ polymorphs during storage or upon heating. Similar results were reported by Santacatalina et al. (2011). Montoyama et al. (2012) applied Raman spectroscopy to study the crystallinity and polymorphism of the fat in adipose tissue and observed a gradual $\beta$ ' to $\beta$ transformation during cooling of the carcass at $4^{\circ} \mathrm{C}$.

Research papers regarding the isothermal crystallization behaviour of lard are quite limited. Kalnin et al. (2005) used DSC and XRD to study the transitions during isothermal crystallization at -10 and $15^{\circ} \mathrm{C}$ during $30 \mathrm{~min}$. They, however, only studied the DSC melting profiles following the isothermal conditioning between 0 and $10 \mathrm{~min}$ and did not show and discuss the XRD results regarding the isothermal conditioning at $15^{\circ} \mathrm{C}$. At $-10^{\circ} \mathrm{C}$, the authors concluded that lard first crystallizes in the $\alpha$ polymorph, which disappears in favour of the $\beta$, polymorph upon further crystallization. The authors could not fully describe the isothermal crystallization at $-10^{\circ} \mathrm{C}$ as the crystallization process was not yet completed at the end of their analysis. deMan et al. (1991) studied the crystallization behaviour at $21^{\circ} \mathrm{C}$ of several lard shortenings and found them to crystallize predominantly in the $\beta$ polymorphic form. Santacatalina et al. (2011) used ultrasonic velocity measurements and DSC to monitor isothermal lard crystallization. They observed two steep increases in ultrasonic velocity when crystallizing at 0,3 and $5^{\circ} \mathrm{C}$ and attributed them to the crystallization of more saturated and more unsaturated TAG fractions, respectively. Crystallization at higher temperatures $(7,10$ and $20^{\circ} \mathrm{C}$ ) only showed one increase in ultrasonic velocity as the most unsaturated triglyceride fraction did not crystallize at those temperatures. Campbell et al. (2002) studied the isothermal crystallization of lard in bulk and emulsified form by means of DSC, nuclear magnetic resonance (NMR) spectrometry and XRD at 15, 17.5, 20 and $22.5^{\circ} \mathrm{C}$. They, however, only studied the isothermal crystallization with XRD at $22^{\circ} \mathrm{C}$ and only showed and discussed the DSC melting profiles following the isothermal conditioning after 5 and $60 \mathrm{~min}$ at $15^{\circ} \mathrm{C}$. At $22^{\circ} \mathrm{C}$, the authors concluded that both lard in bulk and emulsified form crystallizes into a mixture of $\beta$ ' and $\beta$ crystals. At $15^{\circ} \mathrm{C}$, they found a shift in the DSC melting peak of both lard systems between 5 and 60 min and attributed this to an $\alpha \rightarrow \beta$, or $\alpha \rightarrow \beta$ polymorphic transition. 
None of the above mentioned articles fully characterized the different crystalline structures during the isothermal crystallization at different temperatures and related them to the thermal behaviour. Therefore, the aim of this research was to investigate in detail the isothermal crystallization mechanism of lard at 18,20, 22 and $24^{\circ} \mathrm{C}$. DSC, time-resolved small-angle X-ray scattering (SAXS) and wide-angle X-ray diffraction (WAXD) were used to elucidate a potential isothermal crystallization mechanism of lard at these temperatures.

\section{Materials en methods}

\subsection{Rendered lard}

Fresh pork back fat (mixture of Belgian Landrace \& Belgian Large White) was provided by Spekindustrie Van Maele (Diksmuide, Belgium). The back fat was trimmed of meat adhering to it, chopped into small cubes $\left(30 \mathrm{~cm}^{3}\right)$ and frozen $\left(-18^{\circ} \mathrm{C}\right)$ until rendered lard preparation. Rendered lard, further called lard, was manufactured by heating the back fat during 30 minutes at $110^{\circ} \mathrm{C}$. Afterwards, the liquid fat was filtered to obtain the lard.

\subsection{DSC}

Isothermal crystallization and stop-and-return experiments were performed with a Q2000 DSC with a refrigerated cooling system and autosampler (TA Instruments, New Castle, USA). The instrument was calibrated prior to analysis with indium (TA Instruments, New Castle, USA). Nitrogen was used to purge the system. About $10 \mathrm{mg}$ of lard was transferred into an aluminium pan and hermetically sealed. An empty pan was used as a reference. For the isothermal crystallization, the following time-temperature procedure was applied: heating to $74^{\circ} \mathrm{C}$ and holding for 10 minutes to ensure complete melting and elimination of crystal memory, cooling at $5^{\circ} \mathrm{C} / \mathrm{min}$ to the isothermal crystallization temperature $\left(18,20,22,24^{\circ} \mathrm{C}\right)$ and holding at this temperature until crystallization was completed. Analyses were performed in triplicate. The DSC profiles were analysed using the TA Universal Analysis software version 4.5A provided by the manufacturer. For the stopand-return experiments, the isothermal crystallization procedure was interrupted at certain isothermal periods and the sample subsequently melted at $25^{\circ} \mathrm{C} / \mathrm{min}$ to $80^{\circ} \mathrm{C}$. The isothermal crystallization period previous to melting varied between 0 and $80 \mathrm{~min}$. A heating rate of $25^{\circ} \mathrm{C} / \mathrm{min}$ was chosen to prevent the occurrence of polymorphic transitions during melting as much as possible so that the melting profiles obtained after the isothermal period give correct information on the fraction(s) that ha(s)(ve) crystallized and/or the polymorphic form(s) in which the fat has crystallized (Foubert et al., 2008). 


\subsection{Time-resolved synchrotron XRD}

Time-resolved SAXS and WAXD experiments were performed at DUBBLE, the

143 Dutch-Belgian beamline (BM26) at the European Synchrotron Radiation Facility (ESRF;

144 Grenoble, France) using a wavelength, $\lambda$, of $1.033 \AA$. The samples were presented in

145 hermetically sealed aluminium DSC pans and the temperature was controlled by a Linkam

146 HFS 191 Heating/Freezing stage (Surrey, United Kingdom). The SAXS patterns were

147 collected on a two-dimensional Pilatus $1 \mathrm{M}$ detector placed at $2 \mathrm{~m}$ from the sample after an

148 evacuated tube. The WAXD signals were captured on a Pilatus 300K-W detector put closely

149 to the sample. The scattering angles were calibrated using silver behenate and high density

150 polyethylene standards. The 2D SAXS and WAXD data were azimuthally averaged using the

151 program ConeX (Gommes \& Goderis, 2010), normalized to the intensity of the incoming

152 beam measured by a photodiode placed downstream from the sample and corrected for the

153 empty holder scattering. The data are represented as a function of the scattering angle, $2 \theta$,

$154(\lambda=1.033 \AA)$. For SAXS the range $0.13<2 \theta<4.2^{\circ}$ is covered and for WAXD the range $8<$ $1552 \theta<25^{\circ}$.

156 SAXS and WAXD data were acquired simultaneously in consecutive $15 \mathrm{~s}$ time 157 frames, composed of $13.6 \mathrm{~s}$ measuring time and $1.4 \mathrm{~s}$ data saving time. During experiment 1 , 158 the sample was cooled from $75^{\circ} \mathrm{C}$ at $5^{\circ} \mathrm{C} / \mathrm{min}$ down to $18^{\circ} \mathrm{C}$ and kept at that temperature for $15990 \mathrm{~min}$ after which it was heated at $10^{\circ} \mathrm{C} / \mathrm{min}$ up to $70^{\circ} \mathrm{C}$. In experiment 2 , the sample was 160 cooled from $75^{\circ} \mathrm{C}$ at $5^{\circ} \mathrm{C} / \mathrm{min}$ down to $20^{\circ} \mathrm{C}$ and kept at that temperature for $50 \mathrm{~min}$ after 161 which it was heated at $10^{\circ} \mathrm{C} / \mathrm{min}$ up to $70^{\circ} \mathrm{C}$.

\subsection{Statistical analysis}

164 The DSC crystallization parameters were analysed by analysis of variance (ANOVA) 165 (SPSS 16.0). Duncan's multiple range test was used to determine the significant differences $166 \quad(P<0.05)$ between means.

\section{Results}

DSC was used to study the isothermal crystallization of lard at $18^{\circ} \mathrm{C}, 20^{\circ} \mathrm{C}, 22^{\circ} \mathrm{C}$ and $24^{\circ} \mathrm{C}$. More knowledge about the isothermal crystallization mechanism of lard was obtained

171 by interrupting the isothermal crystallization process after different isothermal periods and 172 subsequent melting of the samples (stop-and-return experiments). The peak area of the 
173 obtained melting profiles gives information on the amount of fat crystallization while shifts in peak maximum give information on possible polymorphic transitions and/or fractional crystallization. Time-resolved XRD using synchrotron radiation was performed to unequivocally identify the polymorphic forms of the DSC crystallization and melting peaks.

177

178

\subsection{Fatty acid composition}

The fatty acid composition, shown in Table 1, was determined according to the method described by Ryckebosch et al. (2012). The fatty acid profile was in good agreement with other studies (Kallio et al., 2001; Marikkar \& Yanty, 2014; Yanty et al., 2012).

\subsection{Isothermal crystallization behaviour of lard using DSC}

Fig. 1 shows the DSC isothermal crystallization curves of lard studied at four different temperatures: $18,20{ }^{\circ} \mathrm{C}$ (Fig. 1A) and $22,24^{\circ} \mathrm{C}$ (Fig. 1B). The peak maxima of the crystallization peaks $\left(t_{\text {peak }}\right)$ were calculated from the DSC crystallization curves. Due to possible crystallization during the preceding cooling, especially at $18^{\circ} \mathrm{C}$, it was decided to calculate the total enthalpy $\left(\Delta H_{\mathrm{tot}}\right)$ from the melting curves instead of from the isothermal crystallization curves. When the fat starts to crystallize during cooling, the crystallization peak is superimposed on the heat flow caused by the change of temperature and can therefore not be integrated (Foubert et al., 2008). Both variables, determined for the different isothermal temperatures studied, are presented in Table 2.

The DSC crystallization curve at $18^{\circ} \mathrm{C}$ (Fig. 1A) displays three exothermal crystallization peaks which are indicated with an arrow and labelled peak I (between 0.5 and $1.8 \mathrm{~min}$ isothermal time), peak II (between 1.8 and $10.2 \mathrm{~min}$ ) and peak III (between 10.2 and $43.3 \mathrm{~min}$ ), in order of appearance. Peak III is enlarged because of its low intensity. As shown in Fig. 1A, a higher isothermal temperature of $20^{\circ} \mathrm{C}$ resulted in the disappearance of peak I (or merging with peak II) while $t_{\text {peak }}$ of peak II was not significantly affected (Table 2). Peak III on the other hand shifted to a significantly longer $\mathrm{t}_{\mathrm{peak}}$ and broadened. Furthermore, $\Delta H_{\text {tot }}$ was significantly lower at $20^{\circ} \mathrm{C}$ compared to $18^{\circ} \mathrm{C}$.

The DSC crystallization curves of $22^{\circ} \mathrm{C}$ and $24^{\circ} \mathrm{C}$ are presented in Fig. 1B on a smaller y-axis because of their lower crystallization intensity. Although lower in intensity, a DSC crystallization curve comparable to the one obtained at $20^{\circ} \mathrm{C}$ was observed for $22^{\circ} \mathrm{C}$. As the isothermal crystallization temperature increased to $22^{\circ} \mathrm{C}$, peak II shifted to a significantly longer $t_{\text {peak }}$ (Table 2) and clearly became broader while $t_{\text {peak }}$ of peak III was not affected. Further increasing the temperature to $24^{\circ} \mathrm{C}$ resulted in a shift of peak II to a significantly 
longer $t_{\text {peak }}$ while $t_{\text {peak }}$ of peak III shifted to shorter times. Consequently, peak II and peak III merged together and were not completely separated. Regarding $\Delta H_{\text {tot }}$, the value decreased significantly with increasing crystallization temperature.

The DSC crystallization curve at $18^{\circ} \mathrm{C}$ implies that lard crystallizes in three steps while the DSC crystallization curves at 20,22 and $24^{\circ} \mathrm{C}$ indicate a two-step crystallization process. In general, such multi-stage crystallization processes can either be the result of polymorphic transitions and/or the crystallization of different fractions that have crystallized (Foubert et al., 2006). This will be further clarified by the stop-and-return and XRD experiments.

\subsection{Stop-and-return experiments of lard using DSC}

The stop-and-return DSC method was applied to gain more information about the multi-stage crystallization process. The melting curves after a selection of isothermal periods at $18,20,22$ and $24^{\circ} \mathrm{C}$ are plotted in Fig. 2. It can be seen that the crystallization mechanism at $18^{\circ} \mathrm{C}$ (Fig. 2A) was different from that observed at $20^{\circ} \mathrm{C}$ (Fig. 2B), $22^{\circ} \mathrm{C}$ (Fig. 2C) and $24^{\circ} \mathrm{C}$ (Fig. 2D).

At $18^{\circ} \mathrm{C}$, when the crystallization was interrupted after 0.5 min (i.e. in peak I (Fig. 1A)), a melting peak with a maximum at $27.0^{\circ} \mathrm{C}$ (Fig. 2A, peak 1) was observed. This peak gradually increased as the isothermal period increased $(1 \mathrm{~min})$. After $2 \mathrm{~min}$, at the end of peak I and the beginning of peak II (Fig. 1A), a second higher-melting peak (Fig. 2A, peak 2) with a maximum at $29.8^{\circ} \mathrm{C}$ appeared. This shift in peak maximum is most probably associated with a polymorphic transition from a metastable to a more stable polymorph (Foubert et al., 2008). When the crystallization was interrupted in peak II (Fig. 1A), starting from 3 min, peak 1 completely disappeared while peak 2 steadily increased. The higher increase of the area of peak 2 compared to the decrease of the area of peak 1 (Fig. 2A) suggests that apart from the polymorphic transition, extra crystals in the more stable polymorph were formed directly from the melt. Interrupting the isothermal crystallization process during peak III (Fig. 1A), after 20 min, resulted in a further increase of peak 2 while a third melting peak (Fig. 2A, peak 3) with a maximum at $36.2^{\circ} \mathrm{C}$ gradually appeared. This probably means that on the one hand extra crystals with a melting point around $30^{\circ} \mathrm{C}$ are formed from the melt, while on the other hand crystals with a melting point around $36^{\circ} \mathrm{C}$ are formed due to another polymorphic transition of a specific fraction to a more stable polymorph.

As can be seen from the melting profiles in Fig. 2B, the crystallization behaviour of lard at $20^{\circ} \mathrm{C}$ is different from that at $18^{\circ} \mathrm{C}$. Only two different melting peaks (peak 2 and peak 
3) can be observed while at $18^{\circ} \mathrm{C}$, three melting peaks could be determined. As shown in Fig.

$2421 \mathrm{~A}$, the isothermal crystallization curve at $20^{\circ} \mathrm{C}$ showed no crystallization peak I which probably explains the absence of a first melting peak around $27^{\circ} \mathrm{C}$ in Fig. $2 \mathrm{~B}$. Consequently, interrupting the crystallization during peak II (Fig. 1A), after $2 \mathrm{~min}$, led to the appearance of a first melting peak (Fig. 2B, peak 2) with a maximum at $30.4^{\circ} \mathrm{C}$, probably indicating direct crystallization from the melt, instead of via a polymorphic transition as at $18^{\circ} \mathrm{C}$. When the crystallization was interrupted during crystallization peak III (Fig. 1A), after 20 min, the same events occurred as at $18^{\circ} \mathrm{C}$. Melting peak 2 (Fig. 2B) increased and simultaneously, another melting peak (peak 3) with a maximum at $37.1^{\circ} \mathrm{C}$ started to appear. Thus again, most probably crystals with a melting point around $30^{\circ} \mathrm{C}$ are further formed from the melt while a polymorphic transition of a specific fraction to an even more stable polymorphic form gives rise to crystals with a peak maximum around $37^{\circ} \mathrm{C}$.

At an isothermal crystallization temperature of $22^{\circ} \mathrm{C}$ and $24^{\circ} \mathrm{C}$, similar events as at $20^{\circ} \mathrm{C}$ were observed. As shown in Fig. $2 \mathrm{C}$ and D, also two melting peaks were observed. After 4 min of isothermal crystallization at $22^{\circ} \mathrm{C}$, melting peak 2 with maximum at $31.3^{\circ} \mathrm{C}$ was already present and it further increased after longer isothermal times. Interrupting the isothermal crystallization process during peak III (Fig. 1B) showed a further increase of melting peak 2 and an appearance of peak 3 with maximum at $38.0^{\circ} \mathrm{C}$ (Fig. 2C). At an isothermal crystallization temperature of $24^{\circ} \mathrm{C}$, a peak 2 with maximum at $34.1^{\circ} \mathrm{C}$ started to appear after $10 \mathrm{~min}$ isothermal time (Fig. 2D). It gradually increased and after $50 \mathrm{~min}$ (in peak III, Fig. 1B) peak 3 with maximum at $39^{\circ} \mathrm{C}$ appeared.

The results of the DSC stop-and-return experiments confirm that the isothermal crystallization of lard at $18^{\circ} \mathrm{C}$ is a three-step process, while at 20,22 and $24^{\circ} \mathrm{C}$ it is a two-step process. They also show that most probably the multi-step crystallization process of lard is the result of polymorphic transition(s).

\subsection{Isothermal crystallization behaviour of lard by time-resolved synchrotron XRD}

Time-resolved XRD using synchrotron radiation was applied to identify the polymorphic transitions indicated by the DSC stop-and-return method. SAXS and WAXD diffraction patterns were monitored simultaneously during the isothermal crystallization at $18^{\circ} \mathrm{C}$ and $20^{\circ} \mathrm{C}$.

Fig. 3 shows the SAXS and WAXS diffraction patterns of the isothermal 273 crystallization of lard at $18^{\circ} \mathrm{C}$. Between 0 and $1.7 \mathrm{~min}$ a first SAXS peak appeared at $2742 \theta=1.23^{\circ}(\mathrm{d}=48.0 \AA)$, indicating the start of the isothermal crystallization process. 
According to literature, TAGs with a long spacing (LS) between $30-50 \AA$ correspond to a double chain length structure (2L) (Lopez et al., 2000). At the same time, a broad WAXD peak at $2 \theta=13.0^{\circ}(\mathrm{d}=4.56 \AA)$ (peak not indicated), indicative of TAGs in the liquid state or disorganized state, slightly decreased while another very weak WAXD peak superimposed on that signal appeared at $2 \theta=14.2^{\circ}(\mathrm{d}=4.17 \AA)$. This WAXD peak can be attributed to an unstable $\alpha$ polymorphic form. (Larsson, 1966; Sato et al., 1999; Timms, 1984).

Between 1.7 and 5.4 min a second broad peak at $2 \theta=1.69^{\circ}(\mathrm{d}=35.1 \AA)$ and a third small peak at $2 \theta=2.62^{\circ}(\mathrm{d}=22.6 \AA)$ gradually appeared while the first peak at $1.23^{\circ}(48.0 \AA)$ started to diminish. The lamellar structure observed at $35.1 \AA$ could correspond to the first order reflection of a $2 \mathrm{~L}$ packing or to the second order of a trilayered (3L) structure with the first order reflection at $22.6 \AA$. This will be further discussed in section 4.1. At the same time, the WAXD diffraction patterns showed the appearance of two peaks $(2 \theta=15.4 ; \mathrm{d}=3.85 \AA$ and $2 \theta=14.2^{\circ} ; \mathrm{d}=4.17 \AA$ ) superimposed on the liquid signal, characteristic of a $\beta$, polymorph (Larsson, 1966; Sato et al., 1999; Timms, 1984). The increase of the $\beta$ ' peak area is much higher than the decrease of the $\alpha$ peak area, indicating additional formation of the $\beta$, polymorph directly from the melt when all $\alpha$ crystals were transformed.

After about 17 min, a small fourth SAXS peak at $2 \theta=1.38^{\circ}(\mathrm{d}=42.9 \AA)$ gradually started to appear underneath the $1.69^{\circ}(35.1 \AA)$ peak. The latter further increased but clearly became narrower while the peak at $2.62^{\circ}(22.6 \AA)$ became more clear. Simultaneously another SAXS peak at $2 \theta=0.89^{\circ}(\mathrm{d}=66.2 \AA)$ became clear which was previously probably hidden in the broad SAXS peak at $1.69^{\circ}(35.1 \AA)$. According to literature a lamellar packing of $42.9 \AA$ corresponds to a 2L stacking. Concurrently, the WAXD diffraction patterns showed an extra peak at $2 \theta=12.9^{\circ}(\mathrm{d}=4.60 \AA)$, which can unequivocally be attributed to a $\beta$ polymorph (Larsson, 1966; Sato et al., 1999; Timms, 1984). So from that moment on, it can be assumed that a second polymorphic transition of a certain TAG fraction took place from a $\beta$ ' to a $\beta$ polymorph while crystallization in $\beta$ ' crystals of the other TAG fractions directly from the melt continued. There are also two peaks apparent at $2 \theta=13.8^{\circ}(4.30 \AA)$ and $2 \theta=14.7^{\circ}$ ( $d=4.04 \AA$ ) which are indicative of a monoclinic subcell, coexisting with the triclinic subcell (Abrahamsson et al., 1978).

Fig. 4 shows the SAXS and WAXD diffraction patterns of the isothermal crystallization of lard at $20^{\circ} \mathrm{C}$. Similar events as for $18^{\circ} \mathrm{C}$ were observed. After 2.25 min a small SAXS peak at $2 \theta=1.20^{\circ}(\mathrm{d}=49.3 \AA)$ started to appear simultaneously with a small WAXD diffraction peak at $2 \theta=14.2^{\circ}(\mathrm{d}=4.17 \AA)$, thus corresponding to $\alpha$ crystals with a $2 \mathrm{~L}$ stacking. This small peak grew and subsequently vanished rapidly favouring the appearance 
of a peak at $2 \theta=1.66^{\circ}(\mathrm{d}=35.6 \AA)$, which already started to grow from 3.5 min onwards.

310 Simultaneously another small peak at $2 \theta=2.60(\mathrm{~d}=22.7 \AA)$ appeared. In the WAXD

311 diffraction patterns, two peaks are visible at $2 \theta=14.2^{\circ}(\mathrm{d}=4.17 \AA)$ and $2 \theta=15.4^{\circ}$

$312(\mathrm{~d}=3.85 \AA)$, suggesting that an $\alpha \rightarrow \beta$ ' polymorphic transition took place. Furthermore,

313 similar to the crystallization at $18^{\circ} \mathrm{C}$, the SAXS peak at $1.66^{\circ}$ further increased until the end

314 of the crystallization. From about 20 min onwards, both peaks at $1.66^{\circ}$ and $2.60^{\circ}$ became

315 narrower, gradually favouring the appearance of another SAXS peak at $2 \theta=1.37^{\circ}$

$316(\mathrm{~d}=43.17 \AA)$, indicative of a $2 \mathrm{~L}$ lamellar packing. A very small peak could be detected

317 around $2 \theta=0.89^{\circ}(\mathrm{d}=66 \AA)$. Concurrently, in the WAXD diffraction pattern, a peak at

$3182 \theta=12.9^{\circ}(\mathrm{d}=4.60 \AA)$ appeared. An $\beta^{\prime} \rightarrow \beta$ polymorphic transition of a certain TAG fraction

319 thus took place. Similar as for $18^{\circ} \mathrm{C}$, there are also two peaks apparent at $2 \theta=13.8^{\circ}(4.30 \AA)$

320 and $2 \theta=14.7^{\circ}(\mathrm{d}=4.04 \AA$ ) which are indicative of a monoclinic subcell (Abrahamsson et al.,

321 1978).

322 The appearance and vanishing of the different XRD peaks confirmed that the 323 isothermal crystallization at $18^{\circ} \mathrm{C}$ is a three-step crystallization which can be attributed to two polymorphic transitions: an $\alpha \rightarrow \beta^{\prime}$ transition in the beginning and a $\beta^{\prime} \rightarrow \beta$ transition of a certain TAG fraction at the end of the crystallization. The results at $20^{\circ} \mathrm{C}$ are however in contrast to the results obtained by the DSC stop-and-return method. While the latter suggested a two-step crystallization process, the former showed a three-step crystallization process similar to at $18^{\circ} \mathrm{C}$, although the amount of $\alpha$ polymorphs formed was much smaller. This is probably the reason why this $\alpha$ formation was not visible using DSC.

\section{Discussion: comparison of data obtained by DSC and XRD: thermal and structural}

\subsection{Characterization of the crystalline structures}

The comparison of the XRD and DSC data allowed us to relate the structural changes to the thermal behaviour and led to the characterization of the different crystalline structures during the isothermal crystallization of lard. The molecular arrangements of the different crystalline structures are discussed based on the results of the isothermal crystallization process at $18^{\circ} \mathrm{C}$.

Melting peak 1 with a maximum at $27.0^{\circ} \mathrm{C}$ (Fig. 2A) obtained by the DSC stop-and- 
of an unstable $\alpha$ polymorphic form with $2 \mathrm{~L}$ lamellar packing. When Kalnin et al. (2005) studied the isothermal crystallization behaviour of lard at $15^{\circ} \mathrm{C}$ by applying stop-and-return experiments between 0 and $10 \mathrm{~min}$, they also observed a single endotherm at $25^{\circ} \mathrm{C}$ at the start of the isothermal crystallization and attributed this peak to the melting of an (not further defined due to lack of XRD data) unstable form.

This $2 \mathrm{~L} \alpha$ structure is probably formed mainly by the SSS TAGs such as PPSt and PStSt, which represent less than $10 \%$ of the total TAGs in lard (Kallio et al., 2001; Keller et al., 1996). The attribution to the SSS TAGs rather than the USS TAGs is based on the fact that the SAXS diffraction peak at $48.0 \AA\left(2 \theta=1.23^{\circ}\right.$; Fig. 3$)$ is very narrow and sharp, indicative of a crystalline structure of TAGs similar in size and shape. Furthermore, PPSt and PStSt have, as pure components in their $\alpha$ crystal structure, SAXS diffraction lines of respectively 44.6 and $48.5 \AA$ comparable to lard in this study (Boodhoo et al., 2009; Bouzidi \& Narine, 2012a,b) whereas the USS TAGs, consisting mainly of OPSt and OPP in lard, have shorter SAXS diffraction lines of respectively 37.0 and $39.2 \AA$. The clearly lower melting temperature $\left(27.0^{\circ} \mathrm{C}\right)$ of the SSS TAGs in lard compared to the pure components $(\mathrm{PPSt}=$ $50.5^{\circ} \mathrm{C}$; PStSt $=51^{\circ} \mathrm{C}$; Boodhoo et al., 2009; Bouzidi \& Narine, 2012a,b) is due to the large amounts of liquid UUU and UUS TAGs in lard (Keller et al., 1996). This shift of the melting temperature is governed by the Hildebrand equation and was also observed in other high melting SSS TAGs in a low-melting solvent (Dibildox-Alvarado \& Toro-Vasquez, 1997; Ng, 1989).

Melting peak 2 with a maximum of $29.8^{\circ} \mathrm{C}$, obtained by the stop-and-return method (Fig. 2A), coincides with the SAXS diffraction line at $35.1 \AA\left(2 \theta=1.69^{\circ}\right.$; Fig. 3$)$. In literature there has been some discussion regarding the molecular organization giving rise to this diffraction line. The attribution is difficult since it may correspond to a $3 \mathrm{~L}$ stacking representing the second order reflection of $66.2 \AA\left(2 \theta=0.89^{\circ}\right)$ or to the first order reflection of a 2L structure composed of TAGs with a high angle of tilt (Campbell et al., 2002; Kalnin et al., 2005; Keller et al., 1996; Rousseau et al., 1998). When looking at the SAXS diffraction patterns during melting (data not shown), the crystalline forms displaying a LS at $66.2 \AA$, $35.1 \AA$ and $22.6 \AA$ jointly melted. This means that the diffraction line at $35.1 \AA$ is related to the second order reflection of a $3 \mathrm{~L}$ packing with its first order and third order reflections at $66.2 \AA$ and $22.6 \AA$, respectively. The first order reflection at $66.2 \AA$ did not appear simultaneously with the second order at $35.1 \AA$ and the third order at $22.6 \AA$ because it was hidden in the broad peak at $35.1 \AA$ and emerged later when the latter became narrower due to the polymorphic $\beta \rightarrow \beta$ transition. Also, the first order reflection at $66.2 \AA$ was rather weak which coincides 
with its absence in lard (Rousseau et al., 1998) and the pure USS TAGs OPP and OPSt (Lutton, 1951).

Melting peak 2 can thus be attributed to the crystallization of 3L $\beta^{\prime}$ crystals. Given the broadness of the SAXS peak, these 3L $\beta$ ' crystals consist of SSS TAGs (which are formed through a $2 \mathrm{~L} \alpha \rightarrow 3 \mathrm{~L} \beta$ ' polymorphic transition) and USS TAGs (which are formed directly from the melt). The latter consist mainly of OPSt and OPP and represent about $30 \%$ of the fat (Kallio et al., 2001; Kalnin et al., 2005). The $\beta$ ' polymorphic forms of both the pure unsymmetrical molecules OPP and OPSt have 3L structures with second order reflections respectively at $33.0 \AA$ and $34.2 \AA$ and third order reflections at respectively $21.8 \AA$ and $22.3 \AA$, comparable to those of lard in this study. The melting temperature of the pure TAGs in their $\beta^{\prime}$ structure is around $35^{\circ} \mathrm{C}$ for OPP and $40^{\circ} \mathrm{C}$ for OPSt (Lutton, 1951), which is clearly lower than the melting peak 2 observed in this study. Again, this is due to the large amount of liquid material in lard (Keller et al., 1996).

Melting peak 3 with a maximum at $36.2^{\circ} \mathrm{C}$ (Fig. 2A) obtained by the DSC stop-andreturn method at $18^{\circ} \mathrm{C}$ can be attributed to the crystallization of a $\beta$ polymorphic form with $2 \mathrm{~L}$ lamellar packing. These $\beta$ crystals mainly consist of SSS TAGs (Lutton, 1962; Rousseau et al., 1998; Kalnin et al., 2005) and are formed through a polymorphic transition of this fraction from the $\beta$ ' polymorph. When looking at the SAXS diffraction patterns during melting (data not shown), the crystalline forms with an LS at $42.9 \AA$ indeed melted last at temperatures between $39.6^{\circ} \mathrm{C}$ and $43.7^{\circ} \mathrm{C}$. SSS TAGs are indeed known to easily form a $\beta$ polymorph (Rousseau et al., 1998). Furthermore, PPSt and PStSt as pure TAGs have, in their $\beta$ polymorph, SAXS diffraction lines between respectively $41.3-42.5 \AA$ and $43.2-46.5 \AA$ and a melting point between respectively $62.5-63.5^{\circ} \mathrm{C}$ and $65-66.2^{\circ} \mathrm{C}$ (De Jong \& Van Soest, 1978). The melting temperature $\left(36.2^{\circ} \mathrm{C}\right)$ of the $2 \mathrm{~L} \beta$ crystals in lard, is again lower compared to the pure TAGs due to the large amount of liquid mainly UUU and UUS TAGs (Keller et al., 1996). A summary of the different crystalline structures of the polymorphic forms in lard at $18^{\circ} \mathrm{C}$ and their attribution to the DSC melting peaks is given in Table 3 .

\subsection{Potential isothermal crystallization mechanism of lard}

The isothermal crystallization process of lard at $18^{\circ} \mathrm{C}$ and $20^{\circ} \mathrm{C}$ is a three-step crystallization step with the formation of $\alpha, \beta$ and $\beta$ crystals. At higher temperatures of $22^{\circ} \mathrm{C}$ and $24^{\circ} \mathrm{C}$, the crystallization can be assumed (although no XRD results were generated) to be a two-step process with no $\alpha$ crystals and only formation of $\beta$ ' crystals directly from the melt. First, the SAXS diffraction peak attributed to the crystallization of $\alpha$ crystals was clearly 
smaller and already almost not detectable at $20^{\circ} \mathrm{C}$ compared to $18^{\circ} \mathrm{C}$ (Fig. 3 and Fig. 4). As higher crystallization temperatures imply lower crystallization rates favouring the crystallization of more stable polymorphic forms (Himawan et al., 2006), this suggests that probably no $\alpha$ crystals were formed at $22^{\circ} \mathrm{C}$ and certainly not at $24^{\circ} \mathrm{C}$. The big difference in maximum of crystallization peak II between $20^{\circ} \mathrm{C}$ and $22^{\circ} \mathrm{C}$ while no difference was observed between $18^{\circ} \mathrm{C}$ and $20^{\circ} \mathrm{C}$ also suggests a change in crystallization mechanism between $20^{\circ} \mathrm{C}$ and $22^{\circ} \mathrm{C}$.

Based on the results obtained from the stop-and-return and XRD experiments, a potential mechanism for the isothermal crystallization mechanism of lard at different temperatures is schematically proposed in Fig. 5.

\subsection{Effect of isothermal crystallization temperature}

The SAXS diffraction patterns (Fig. 3 and Fig. 4) showed that, although formation of $\alpha$ crystals started later at $20^{\circ} \mathrm{C}$, the polymorphic transition $\alpha \rightarrow \beta$ ' occurred faster at a higher temperature of $20^{\circ} \mathrm{C}$ compared to $18^{\circ} \mathrm{C}$. This coincides with literature. At higher temperature and thus lower driving forces, nucleation occurs latter (Himawan et al., 2006). The rate of polymorphic transitions however increases at higher isothermal crystallization temperatures because the lower stability of the less stable polymorphic forms at higher temperatures increases the driving force for transformation into the more stable polymorphic forms (Ten Grotenhuis et al., 1999; Walstra, 1987). Furthermore, at a higher crystallization temperature of $20^{\circ} \mathrm{C}$ less $\alpha$ crystals were formed compared to $18^{\circ} \mathrm{C}$ because at higher crystallization temperatures and thus lower crystallization rates, the formation of more unstable polymorphic forms is less favoured (Himawan et al., 2006). This also explains why the crystallization of $\alpha$ crystals could not be detected as a separated peak in the DSC at $20^{\circ} \mathrm{C}$.

Furthermore, it is clear from Table 2 and Fig. 1 that higher crystallization temperatures of $22^{\circ} \mathrm{C}$ and $24^{\circ} \mathrm{C}$ resulted in a later start of the $\beta$ ' crystallization which also occurred slower. This can be explained by a decrease in crystallization driving force (Himawan et al., 2006) but also by a difference in crystallization mechanism.

The crystallization of $\beta$ crystals, formed through an $\beta \rightarrow \beta$ ' polymorphic transition at all studied isothermal crystallization temperatures occurs remarkably faster at $24^{\circ} \mathrm{C}$ compared to $22^{\circ} \mathrm{C}$ (Fig. 1, Table 2). This can be attributed to the lower stability of the less stable polymorphic forms and a much larger amount of liquid material (lower $\Delta \mathrm{H}_{\text {tot }}$; Table 2) at higher temperatures favouring the driving force for transformation into more stable polymorphic forms (Ten Grotenhuis et al., 1999; Walstra, 1987). 
Finally, it can be concluded that the higher the isothermal crystallization temperature,

445 the lower the amount of crystallized fat as indicated in Table 2. Furthermore, the melting 446 temperature of the $\beta$ ' and $\beta$ peaks obtained by the stop-and-return method increased with 447 increasing temperature due to crystallization of fewer lower melting TAGs.

\section{Conclusions}

Using DSC and time-resolved XRD, it was shown that the isothermal crystallization process of lard between $18^{\circ} \mathrm{C}$ and $20^{\circ} \mathrm{C}$ is a three-step crystallization process with formation of $\alpha$ crystals in the first step, $\beta$ ' crystals in the second step and finally $\beta$ crystals in the third step. The first step is attributed to the crystallization of trisaturated TAGs with a $2 \mathrm{~L}$ structure in the $\alpha$ polymorph while in the second step $\beta$ ' crystals with a $3 \mathrm{~L}$ structure were formed due to a $2 \mathrm{~L} \alpha \rightarrow 3 \mathrm{~L} \beta$ ' polymorphic transition of the trisaturated TAGs and the crystallization of monounsaturated TAGs directly from the melt. Finally, the crystallization of $\beta$ crystals in the last step is attributed to a second $3 \mathrm{~L} \beta$ ' $\rightarrow 2 \mathrm{~L} \beta$ polymorphic transition of the trisaturated TAGs. Above a cut-off temperature of $20^{\circ} \mathrm{C}$ lard is found to crystallize in two steps with no $\alpha$ crystals and crystallization of the trisaturated and monounsaturated TAGs in the $\beta$ ' polymorph directly from the melt.

\section{Acknowledgements}

The authors acknowledge the financial support from the Research Council of the 464 Katholieke Universiteit Leuven, in particular the Industrial Research Fund and the Fund for 465 Stimulation of Scientific Research for associated technical universities. Annelien Rigolle is a 466 Postdoctoral Fellow of the Fund for Scientific Research Flanders (FWO Vlaanderen). FWO 467 Vlaanderen is also acknowledged for supporting the ESRF/DUBBLE Big Science project 468 (G.0C12.13). 
Abrahamsson, S., Dahlén, B., Löfgren, H., \& Pascher, I. (1978). Lateral packing of hydrocarbon chains. Progress in the Chemistry of Fats and other Lipids, 16, 125-143. Compositional and thermal characterization of genuine and randomized lard: a comparative study. Journal of American Oil Chemists' Society, 73 (3), 303-309.

Boodhoo, M.V., Bouzidi, L., \& Narine, S. S. (2009). The binary phase behaviour of 1, 3-dipalmitoyl-2-stearoyl-sn-glycerol and 1, 2-dipalmityol-3-stearoyl-sn-glycerol.

Bouzidi, L., \& Narine, S. S. (2012a). Relationships between molecular structure and kinetic and thermodynamic controls in lipid systems. Part II: Phase behaviour and transformation paths of SSS, PSS and PPS saturated triacylglycerols-Effect of chain length mismatch. Chemistry and Physics of Lipids, 165, 77-88.

Bouzidi, L., \& Narine, S. S. (2012b). Relationships between molecular structure and kinetic and thermodynamic controls in lipid systems Part III. Crystallization and phase behaviour of 1-palmitoyl-2,3-stearoyl-sn-glycerol (PSS) and tristearoylglycerol (SSS) binary system. Chemistry and Physics of Lipids, 165, 105-119.

Campos, R., Narine, S. S., \& Marangoni, A. G. (2002). Effect of cooling rate on the 488 structure and mechanical properties of milk fat and lard. Food Research International, 35, 971-981.

Campbell, S. D., Goff, H. D., \& Rousseau, D. (2002). Comparison of crystallization properties of a palm stearin/canola oil blend and lard in bulk and emulsified form. Food Research International, 35, 935-944.

De Jong, B. S., \& Van Soest, T. C. (1978). Acta Crystallographica, B34, 1570-1583.

DeMan, L., deMan, J. M., \& Blackman, B. (1991). Physical and textural 495 characteristics of some North American shortenings. Journal of American Oil Chemists' Society, 68 (2), 63-69.

Dibildox-Alvarado, E., \& Toro-Vasquez, J. F. (1997). Isothermal crystallization of tripalmitin in sesame oil. Journal of American Oil Chemists' Society, 74 (2), 69-76.

Foubert, I., Dewettinck, K., Janssen, G., \& Vanrolleghem, P.A. (2006). Modelling two-step isothermal fat crystallization. Journal of Food Engineering, 75, 551-559.

Foubert, I., Fredrick, E., Vereecken, J., Sichien, M., \& Dewettinck K. (2008). Stopand-return DSC method to study fat crystallization. Thermochimica Acta, 471, 7-13. 
Gandemer, G. (2002). Lipids in muscles and adipose tissues, changes during

504

505

506

507

508

509

510

511

512

513

514

515

516

517

518

519

520

521

522

523

524

525

526

527

528

529

530

531

532

533

534

535 processing and sensory properties of meat products. Meat Science, 62, 309-321.

Gommes, C. J., \& Goderis, B. J. (2010). Conex, a program for angular calibration and averaging of two-dimensional powder scattering patterns. Journal of Applied Crystallography, 43, 352-355.

Himawan, C., Starov, V. M., \& Stapley, A. G. F. (2006). Thermodynamic and kinetic aspects of fat crystallization. Advances in Colloid and Interface Science, 122, 3-33.

Kalnin, D., Lesieur, P., Artzner, F., Keller, G., \& Ollivon, M. (2005). Systematic investigation of lard polymorphism using combined DSC and time-resolved synchotron X-ray diffraction. European Journal of Lipid Science Technology, 107, 594-606.

Kallio, H., Yli-Jokipii, K., Kurvinen, J. P., Sjövall, O., \& Tahvonen, R. (2001). Regioisomerism of triacylglycerols in lard, tallow, yolk, chicken skin, palm oil, palm olein, palm stearin, and a transesterified blend of palm stearin and coconut oil analyzed by tandem mass spectrometry. Journal of Agricultural and Food Chemistry, 49, 3363-3369.

Keller, G., Lavign, F., Loisel, C., Ollivon, M. \& Bourgaux, C. (1996). Investigation of the complex thermal behaviour of fats. Journal of Thermal Analysis, 47, 1545-1565.

Kincs, F. R. (1985). Meat fat formulation. Journal of American Oil Chemists' Society, $62(4), 815-818$.

Larsson, K. (1966). Classification of Glyceride crystal forms. Acta Chemica Scandinavica, 20, 2255-2260.

Lopez, C., Lesieur, P., Keller, G., \& Ollivon, M. (2000). Thermal and structural behaviour of milk fat. Journal of Colloid and Interface Science, 229, 62-71.

Lutton, E. S. (1951). The polymorphism of the disaturated triglycerides - OSS, OPP, POS, OPS and OSP. Journal of American Oil Chemists' Society, 73(12), 5595-5598.

Lutton, E. S., Mallery, M. F., \& Burgers, J. (1962). Interesterification of lard. Journal of American Oil Chemists' Society, 39, 233-235.

Marikkar, J. M. N., \& Yanty, N. A. M. (2014). Effect of chemical and enzymatic modifications on the identity characteristics of lard: a review. International Journal of Food Properties, 17, 321-330.

Montoyama, M., Chikuni, K., Narita, T., Aikawa, K., \& Sasaki, K. (2013). Journal of Agricultural and Food Chemistry, 61, 69-75.

$\mathrm{Ng}$, W. L. (1989). Nucleation behaviour of tripalmitin from a trolein solution. Journal of American Oil Chemists' Society, 66 (8), 1103-1106. 
Rousseau, D., Marangoni, A. G. \& Jeffrey K. R. (1998). The influence of chemical interesterification on the physicochemical properties of complex fat systems. 2. Morphology and Polymorphism. Journal of American Oil Chemists' Society, 75, 1833-1839. procedure for extraction of lipids from microalgae. Journal of the American Oil Chemists' Society, 89, 189-198.

Santacatalina, J. V., Garcia-Perez, J. V., Corona, E., \& Benedito, J. (2011). Ultrasonic monitoring of lard crystallization during storage. Food Research International, 44, 146-155.

Sato, K., Ueno, S., \& Yano J. (1999). Molecular interactions and kinetic properties of fats. Progress in Lipid Research, 38, 91-116.

Steen, L., Fraeye, I., De Mey, E., Goemaere, O., Paelinck, H., \& Foubert, I. (2014a). Effect of salt and liver/fat ratio on viscoelastic properties of liver paste and its intermediates. Food and Bioprocess Technology, 7(2), 496-505.

Steen, L., Fraeye, I., Goemaere, O., Sifre, L., Goderis, B., Paelinck, H., \& Foubert, I. (2014b). Effect of salt and liver/fat ratio on microstructure, emulsion stability, texture and sensory mouth feel of liver paste. Food and Bioprocess Technology, 7(10), 2855-2864.

Svenstrup, G., Brüggeman, D., Kristensen, L., Risbo, J., \& Skibsted, L. H. (2005). The influence of pretreatment on pork fat crystallization. European Journal of Lipid Science Technology, 107, 607-615.

Ten Grotenhuis, E., Aken, G. A. (1999). Polymorphism of milk fat studied by differential scanning calorimetry and real-time x-ray powder diffraction. Journal of American Oil Chemists' Society, 76 (9), 1031-1039.

Timms, R.E. (1984). Phase behaviour of fats and their mixtures. Progress in Lipid Research, 23, 1-38.

Walstra, P. (1987). Fat crystallization. In V. M. V. Blanshard, \& P. Lillford (Eds.), Food structure and behaviour (pp. 67-85). London: Academic Press. thermo-physical characteristics of lard and selected plant fats. Gracas y Aceites, 63(3), 328- 
569 Table 1: Fatty acid composition (\%) of lard. Means and standard deviation are presented $570 \quad\left(C_{n}=3\right)$.

571

572 Table 2: Peak maximum of crystallization ( $\left.\mathrm{t}_{\text {peak }}\right)$ and total melting enthalpy $\left(\Delta \mathrm{H}_{\mathrm{tot}}\right)$ for

573 isothermal crystallization of lard at 18, 20, 22 and $24^{\circ} \mathrm{C}$. Means and standard deviation are

574 presented $\left(\mathrm{C}_{\mathrm{n}}=3\right)$.

$575^{\mathrm{a}, \mathrm{b}, \mathrm{c}, \mathrm{d}}$ Effect of isothermal temperature: means with different letter indicate significant

576 difference at $\mathrm{P}<0.05$.

577

578 Table 3: Crystalline structures of the polymorphic forms in lard and their attribution to DSC 579 melting peaks.

580 
582 Table 1

583

\begin{tabular}{lr}
\hline Fatty acid & $(\%)$ \\
\hline C14:1 & $1.50 \pm 0.00$ \\
C16:0 & $24.30 \pm 0.17$ \\
C16:1 & $2.00 \pm 0.00$ \\
C17:0 & $0.30 \pm 0.00$ \\
C17:1 & $0.30 \pm 0.00$ \\
C18:0 & $12.30 \pm 0.10$ \\
C18:1 (n-9) & $39.83 \pm 0.00$ \\
C18:1 (n-7) & $3.10 \pm 0.00$ \\
C18:2 & $13.40 \pm 0.10$ \\
C18:3 (n-3) & $0.90 \pm 0.00$ \\
C20:0 & $0.10 \pm 0.00$ \\
C20:1 & $0.67 \pm 0.06$ \\
C20:2 & $0.50 \pm 0.00$ \\
C20:3 (n-6) & $0.20 \pm 0.00$ \\
C20:3 (n-3) & $0.10 \pm 0.00$ \\
\hline
\end{tabular}

584

585 Each value in the table represents the mean of three replicates

586

587 
Table 2

\begin{tabular}{|c|c|c|c|c|}
\hline & Peak I & Peak II & Peak III & \\
\hline $\begin{array}{l}T_{\text {isotherm }} \\
\left({ }^{\circ} \mathrm{C}\right)\end{array}$ & $\begin{array}{c}t_{\text {peak }} \\
\text { (min) }\end{array}$ & $\begin{array}{c}t_{\text {peak }} \\
\text { (min) }\end{array}$ & $\begin{array}{c}t_{\text {peak }} \\
\text { (min) }\end{array}$ & $\begin{array}{l}\Delta H_{\text {tot }} \\
(\mathrm{J} / \mathrm{g})\end{array}$ \\
\hline 18 & $0.9 \pm 0.1$ & $3.0 \pm 0.1^{\mathrm{a}}$ & $27.7 \pm 1.2^{\mathrm{a}}$ & $29.5 \pm 3.0^{a}$ \\
\hline 20 & I & $2.8 \pm 0.1^{a}$ & $33.6 \pm 0.6^{b}$ & $27.7 \pm 1.2^{b}$ \\
\hline 22 & l & $6.6 \pm 0.3^{b}$ & $34.5 \pm 1.6^{b}$ & $24.9 \pm 0.3^{c}$ \\
\hline 24 & l & $19.9 \pm 3.5^{c}$ & $28.5 \pm 2.3^{a}$ & $20.3 \pm 0.1^{d}$ \\
\hline
\end{tabular}

589

590 Each value in the table represents the mean of three replicates

591 
592 Table 3

\begin{tabular}{|c|c|c|c|c|c|c|}
\hline \multirow{2}{*}{$\begin{array}{l}\text { Lamellar } \\
\text { stacking }\end{array}$} & \multirow{2}{*}{$\begin{array}{l}\text { Polymorphic form } \\
\text { (subcell) }\end{array}$} & \multicolumn{2}{|c|}{ SAXS peaks } & \multicolumn{2}{|c|}{ WAXD peaks } & \multirow{2}{*}{$\frac{\mathrm{DSC}}{{ }^{\circ} \mathrm{C}}$} \\
\hline & & $2 \theta$ & $\AA$ & $2 \theta$ & $\AA$ & \\
\hline $2 \mathrm{~L}$ & $\alpha$ (hexagonal) & 1.23 & 48.0 & 14.2 & 4.17 & 27 \\
\hline \multirow[t]{3}{*}{$3 L$} & $\beta^{\prime}$ (orthorhombic) & 0.89 & 66.2 & 14.2 & 4.17 & 30 \\
\hline & & 1.69 & 35.1 & 15.4 & 3.85 & \\
\hline & & 2.62 & 22.6 & & & \\
\hline $2 \mathrm{~L}$ & $\beta$ (triclinic) & 1.38 & 42.9 & 12.9 & 4.6 & 36 \\
\hline
\end{tabular}

593

594 
597 Fig. 1. Isothermal crystallization curves of lard as measured by DSC at $18^{\circ} \mathrm{C}$ and $20^{\circ} \mathrm{C}$ (A) 598 and at $22^{\circ} \mathrm{C}$ and $24^{\circ} \mathrm{C}$ (B) (exo up).

599

600 Fig. 2. Stop-and-return melting curves of lard crystallized at $18^{\circ} \mathrm{C}(\mathrm{A}), 20^{\circ} \mathrm{C}(\mathrm{B}), 22^{\circ} \mathrm{C}$ (C) 601 and $24^{\circ} \mathrm{C}(\mathrm{D})$ (exo up).

602

603 Fig. 3. SAXS (left graph) and WAXD (right graph) diffraction patterns of the isothermal 604 crystallization of lard at $18^{\circ} \mathrm{C}$.

605

606 Fig. 4. SAXS (left graph) and WAXD (right graph) diffraction patterns of the isothermal 607 crystallization of lard at $20^{\circ} \mathrm{C}$.

608

609 Fig 5. Schematic overview of potential isothermal crystallization mechanism of lard 610 

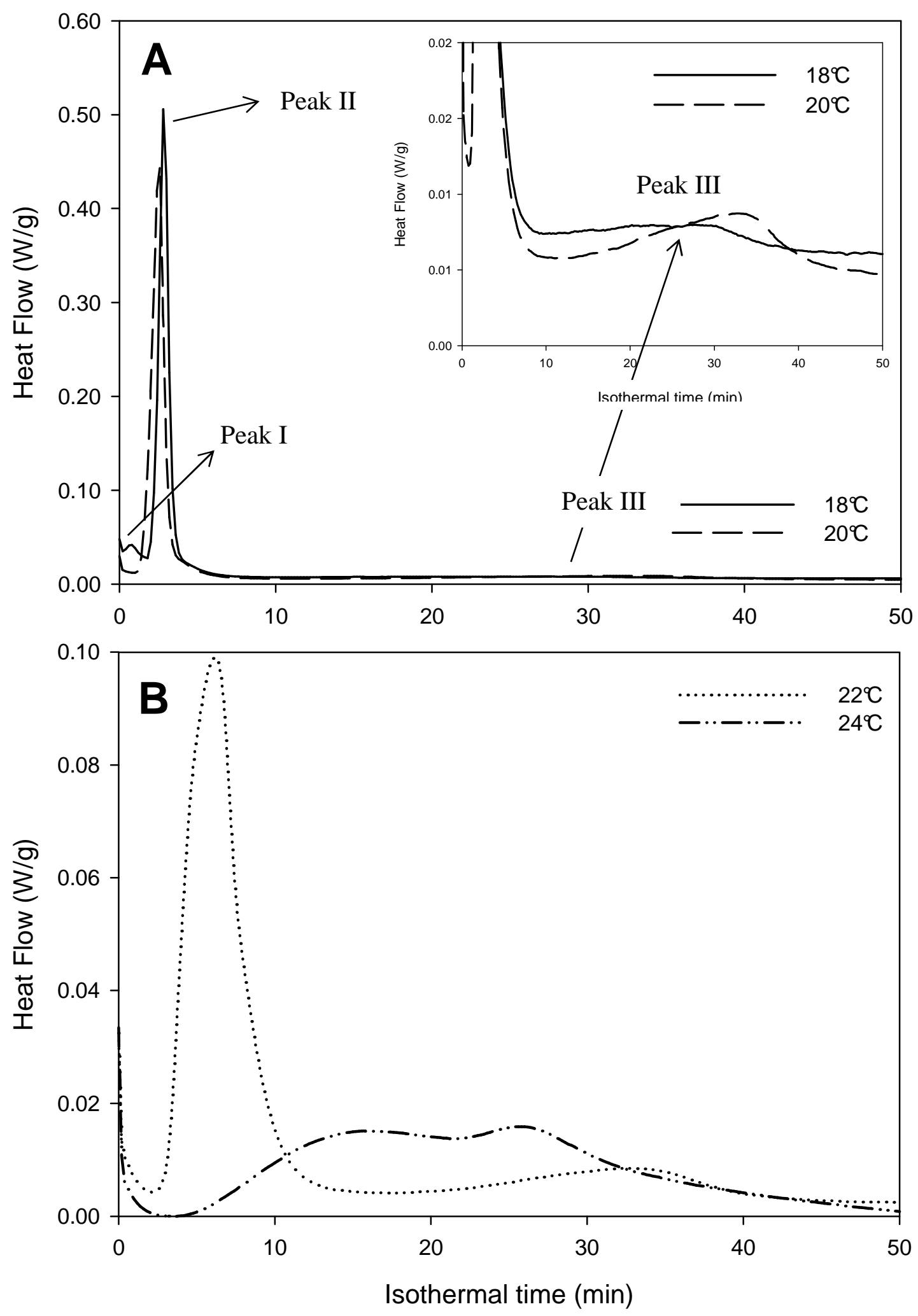

Fig. 1 

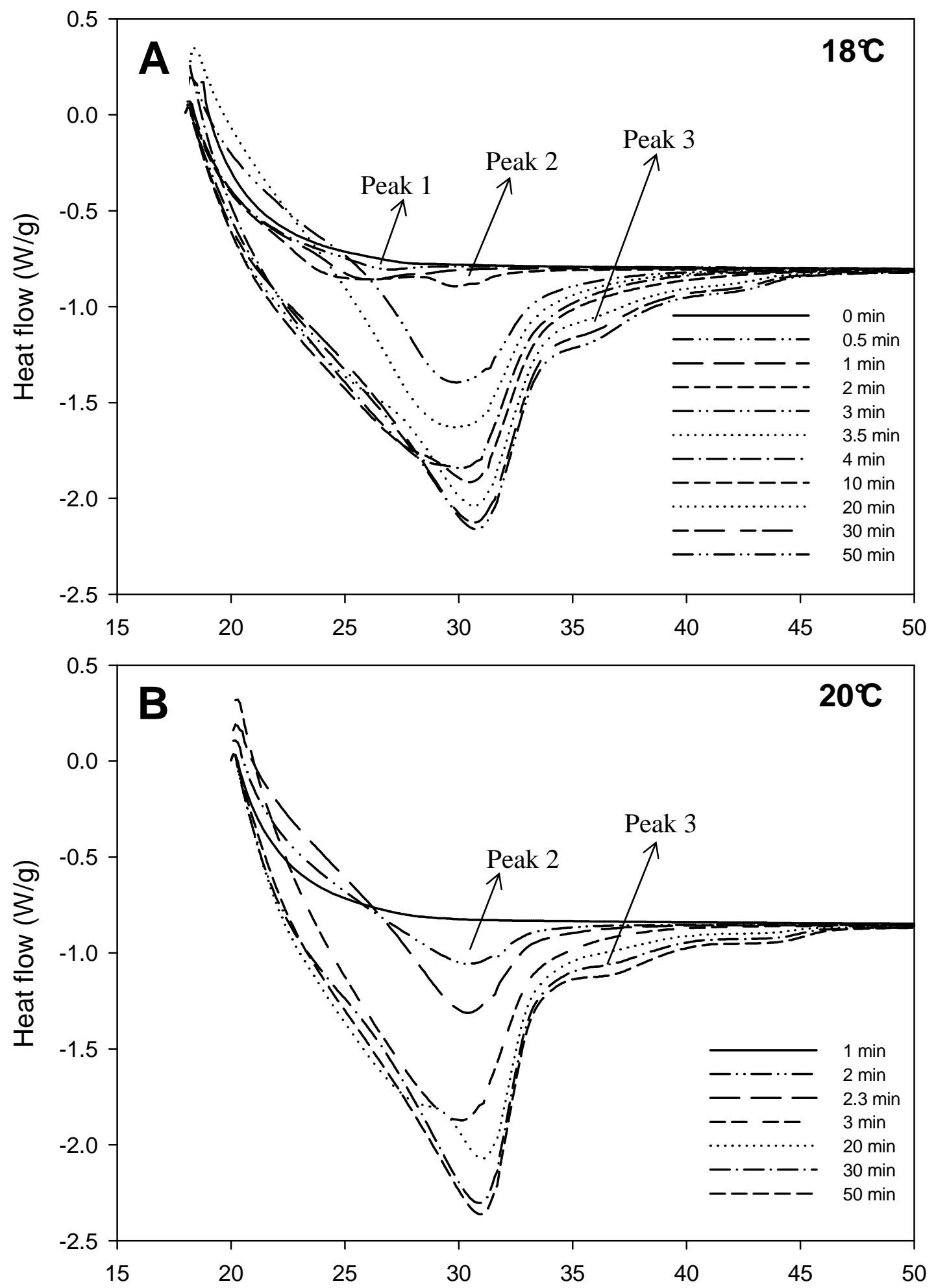

Fig. 2 

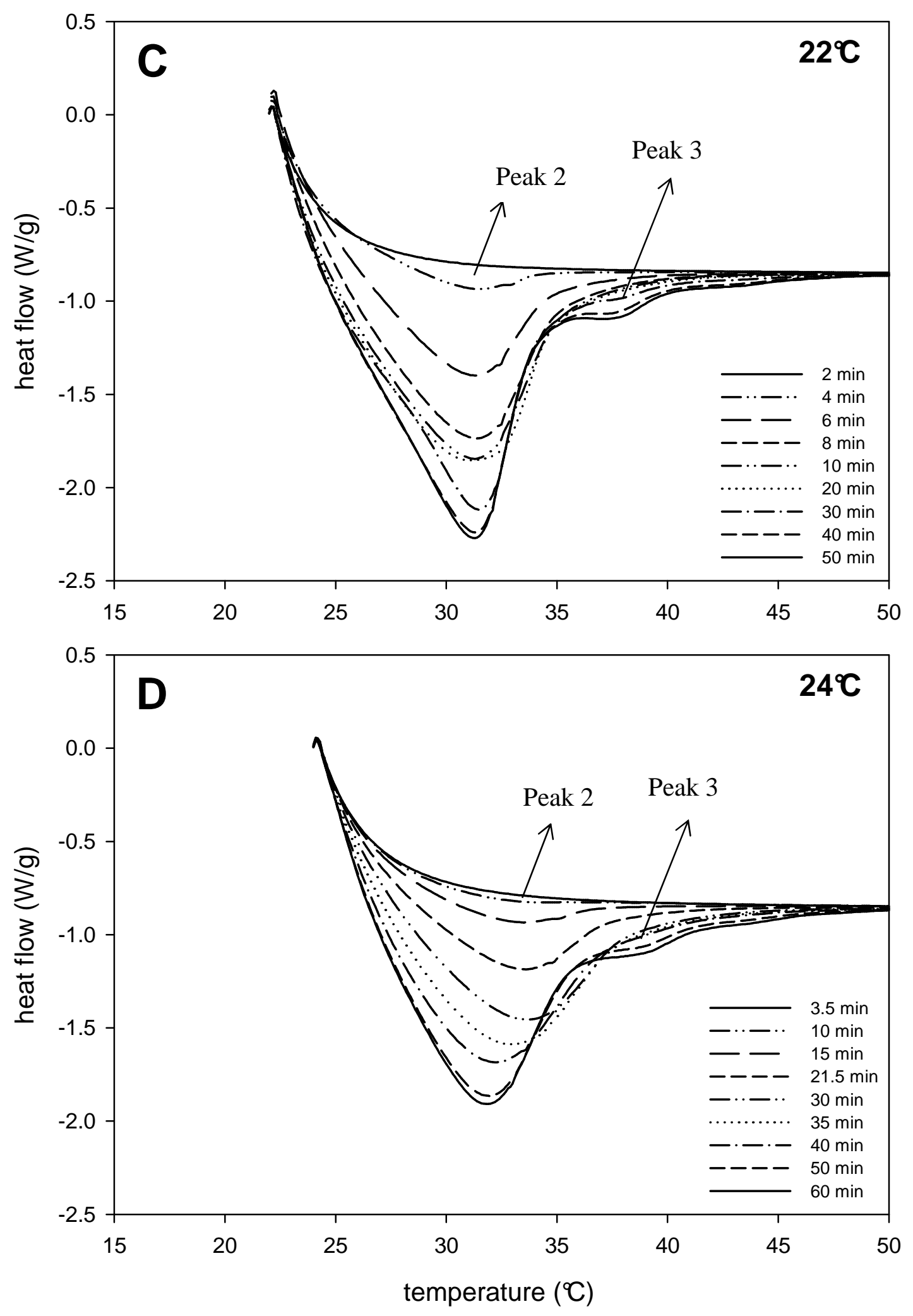

Fig. 2 


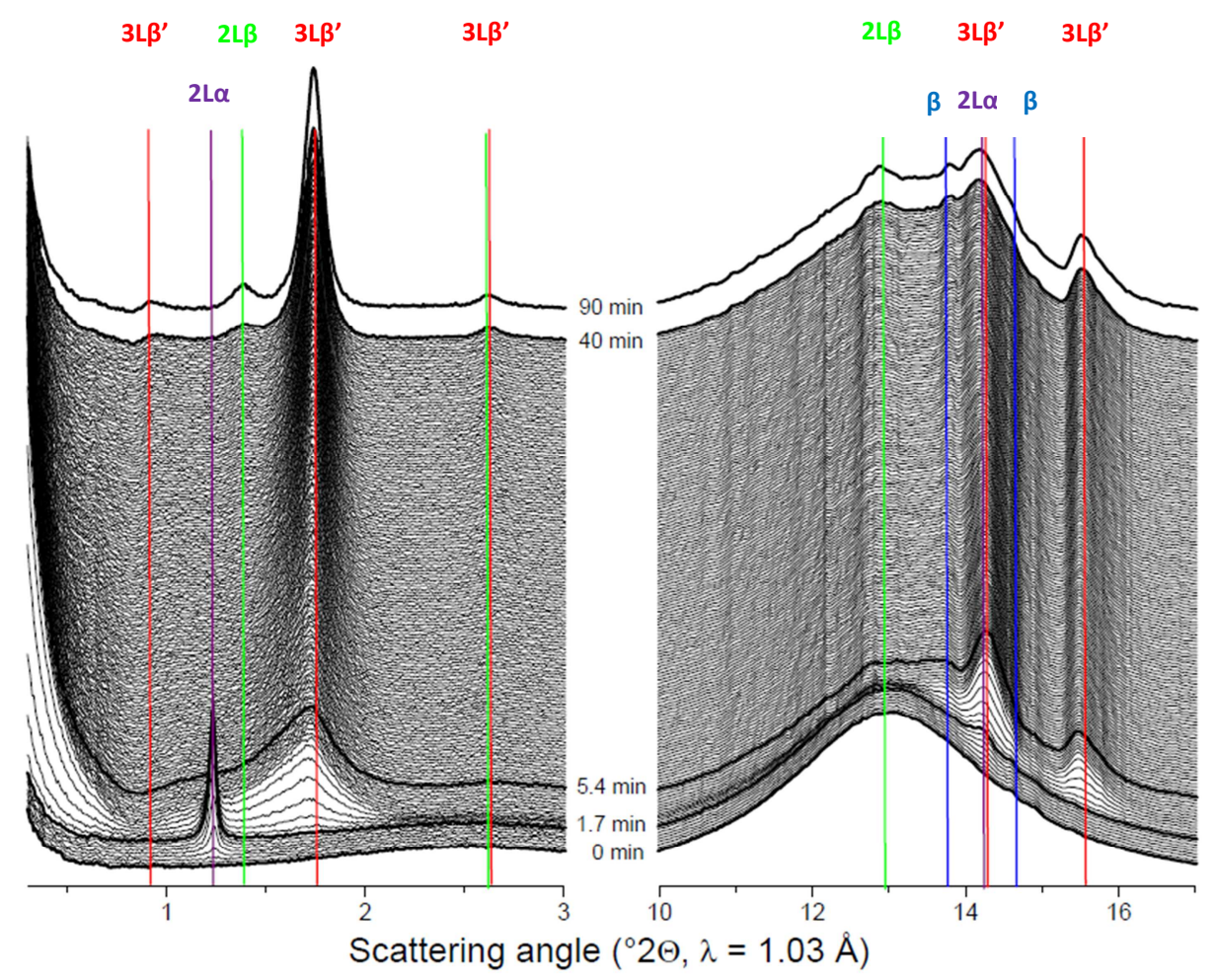

Fig. 3 


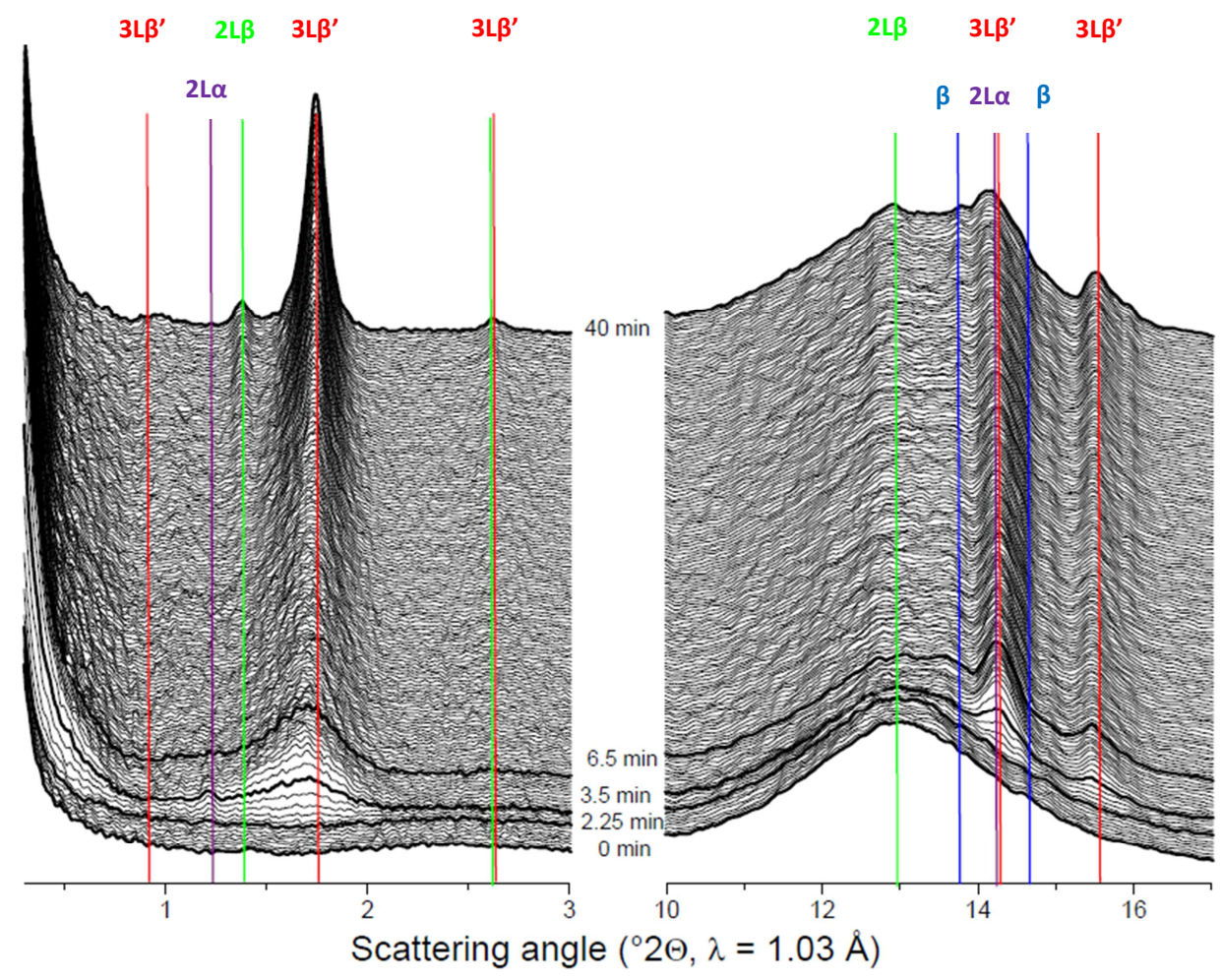

Fig. 4 
Melting peak 1

$27^{\circ} \mathrm{C}$

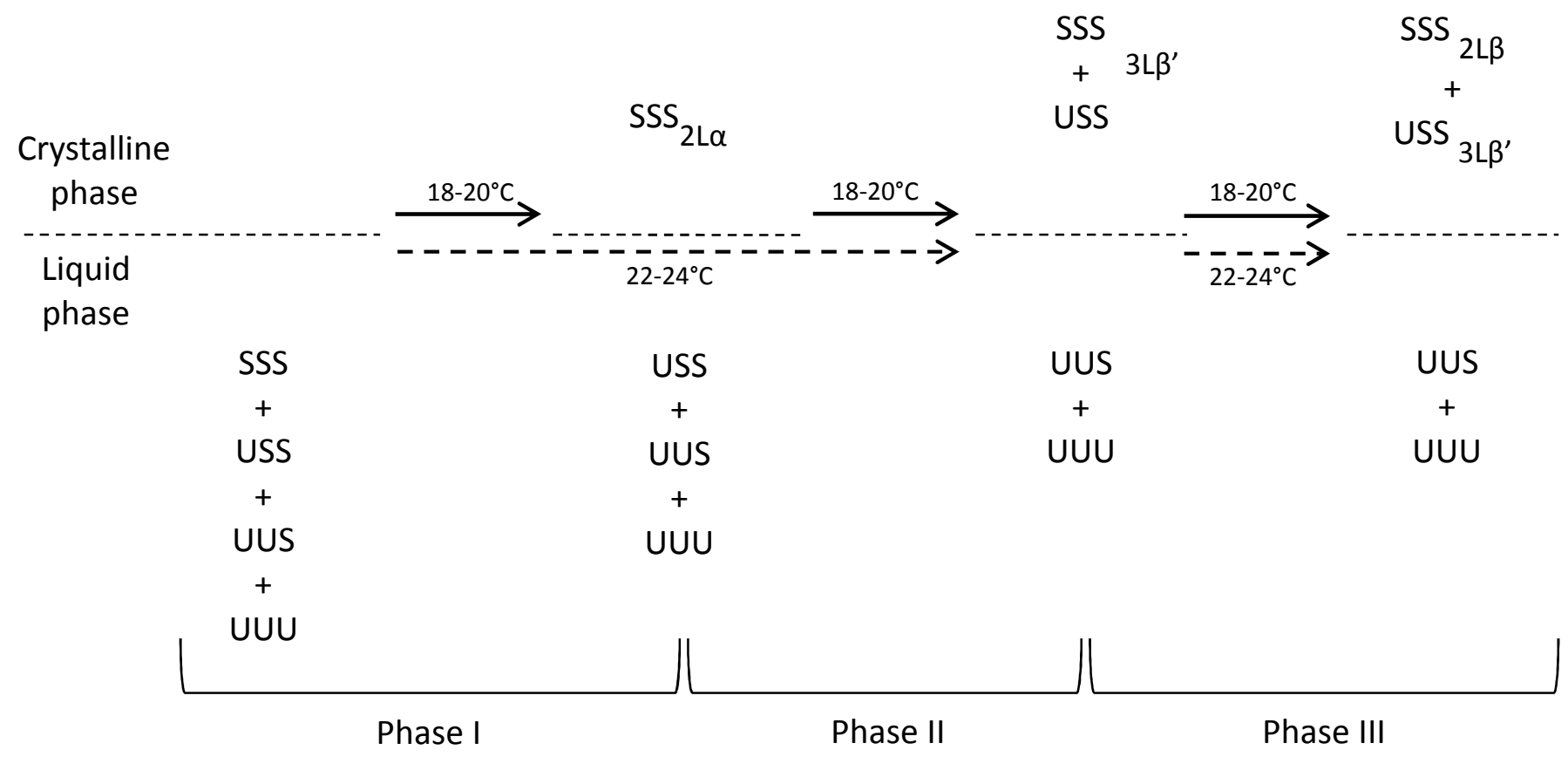

Fig. 5 